\title{
A New Post-Metallocene-Ti Catalyst with Maltolate Bidentade Ligand: an Investigation in Heterogeneous Polymerization Reactions in Different Mesoporous Supports
}

\author{
Grasiela Gheno, ${ }^{a}$ Nara Regina de Souza Basso, ${ }^{b}$ Paolo Roberto Livotto, ${ }^{a}$ Maria Rosário \\ Ribeiro, ${ }^{c}$ João Paulo Lourenço, ${ }^{c, d}$ Ana Elisa Ferreira ${ }^{c}$ and Griselda Barrera Galland ${ }^{* a}$ \\ anstituto de Química, Universidade Federal do Rio Grande do Sul, Avenida Bento Gonçalves, 9500, \\ 91501-970 Porto Alegre-RS, Brazil \\ ${ }^{b}$ Faculdade de Química, Pontifícia Universidade Católica do Rio Grande do Sul, Avenida Ipiranga, \\ 6681, 90619-900 Porto Alegre-RS, Brazil \\ ${ }^{c}$ Centro de Química Estrutural (CQE) e Departamento de Engenharia Química, Instituto Superior \\ Técnico, Universidade de Lisboa, Av. Rovisco Pais, 1049-001 Lisboa, Portugal \\ ${ }^{d}$ Faculdade de Ciências e Tecnologia, CIQA, Universidade do Algarve, Campus de Gambelas, \\ 8005-136 Faro, Portugal
}

\begin{abstract}
A new titanium catalyst easily synthesized from ethylmaltol bidentate chelator ligand was studied in homogeneous and heterogeneous ethylene polymerization. The dichlorobis(3-hydroxy2-ethyl-4-pyrone)titanium(IV) complex was characterized by ${ }^{1} \mathrm{H}$ and ${ }^{13} \mathrm{C}$ NMR (nuclear magnetic resonance), UV-Vis and elemental analysis. Theoretical study by density functional theory (DFT) showed that the complex chlorines exhibit cis configuration, which is important for the activity in olefin polymerization. The complex was supported by two methods, direct impregnation or methylaluminoxane (MAO) pre-treatment, in five mesoporous supports: MCM-41 (micro and nano), SBA-15 and also the corresponding modified Al species. All the catalytic systems were active in ethylene polymerization and the catalytic activity was strongly influenced by the method of immobilization of the catalyst and the type of support.
\end{abstract}

Keywords: catalysis, synthesis, mesoporous support, immobilization, polyethylene

\section{Introduction}

Polyethylene (PE) has a broad application in different segments of the everyday life, from food packaging to resistant pieces for engineering. Due to the polymer industrial demands, continuous development of new technologies and synthetic methods for obtaining this material are necessary. Existing processes, involving polyethylene synthesis in industrial and/or research scale, use Ziegler-Natta, metallocene, and more recently, postmetallocene catalysts. Our research group has studied the synthesis of different post-metallocene catalysts and tested these complexes in ethylene polymerization. Organometallic complexes of $\mathrm{Ti}$ and $\mathrm{Zr}$ were obtained from bidentate chelator ligands as naphthoquinone, methylpyrone, ethylpyrone and 3-hydroxyflavone..$^{1-5}$ All the synthesized complexes were active in homogeneous

*e-mail: griselda.barrera@ufrgs.br ethylene polymerization at different reaction conditions. 3-Hydroxy-2-methyl-4-pyrone (methylpyrone or maltol) is a non-toxic compound of natural occurrence in many plants, ${ }^{6}$ while 3-hydroxy-2-ethyl-4-pyrone (ethylmaltol) is a synthetic commercial product. These organic compounds are commonly used in food industries as flavor ingredients. Both hydroxypyrones are characterized by their synthetic versatility and they easily coordinate with transition metals of group IV to give $\mathrm{L}_{2} \mathrm{MCl}_{2}$ complexes. ${ }^{7} \mathrm{Bis}$ (maltolate) metal(IV) complexes are extensively used in medical studies to assess their therapeutic value as active agents against diabetes, as agents for controlling metal levels in the body and as contrast agents in imaging applications. ${ }^{8-12}$

Maltolate complexes appear attractive to catalyze olefin polymerization reaction as well. In 2001, Sobota et al. ${ }^{13}$ synthesized and characterized titanium complexes of methylmaltol and verified their catalytic activity in ethylene and propylene polymerization. Subsequently, our research group has synthesized several Ti and $\mathrm{Zr}$ complexes 
analogous based in maltolate ligands. The synthesized complexes were shown to be active in the ethylene polymerization in homogeneous and heterogeneous conditions. The dichlorobis(3-hydroxy-2-methyl-4pyrone)zirconium(IV) complex from methylmaltol ligand was shown to be more active in ethylene polymerization (180 kg PE mol-1 atm $\left.^{-1} \mathrm{~h}^{-1}\right)$ than the analogous titanium complex $\left(66 \mathrm{~kg} \mathrm{PE} \mathrm{mol}{ }^{-1} \mathrm{~atm}^{-1} \mathrm{~h}^{-1}\right){ }^{3}$ However, the dichlorobis(3-hydroxy-2-ethyl-4-pyrone)zirconium(IV) complex from ethylmaltol ligand showed a higher catalytic activity $\left(281 \mathrm{~kg} \mathrm{PE} \mathrm{mol}^{-1} \mathrm{~atm}^{-1} \mathrm{~h}^{-1}\right)^{4}$ than the analogue complex from methylmaltol under the same reaction conditions (Al/Zr: 2500; ethylene: $1.6 \mathrm{~atm}$; temperature: $60{ }^{\circ} \mathrm{C}$; time: $60 \mathrm{~min}$ ). We concluded that the substitution of the methyl group by the ethyl group in the pyrone ligand structure enhances the catalytic activity of these complexes.

Some of these post-metallocene complexes have been tested in heterogeneous systems using several supports. In particular, the titanium complex from methylmaltol ligand, dichlorobis(3-hydroxi-2-methyl-4-pyrone)Ti(IV), was immobilized on $\mathrm{SiO}_{2}, \mathrm{SiO}_{2}-\mathrm{MAO}, \mathrm{MCM}-41, \mathrm{Al}_{2} \mathrm{O}_{3}, \mathrm{ZrO}_{2}$ and $\mathrm{MgO}$. These heterogeneous systems were tested in ethylene polymerization, showing higher catalytic activities than the homogeneous systems, being MCM- 41 and $\mathrm{Al}_{2} \mathrm{O}_{3}$ the best supports. ${ }^{2}$

Many types of supports have been used in the preparation of heterogeneous catalytic systems for olefin polymerization. In recent years, research on heterogeneous polymerization involving mesoporous supports such as MCM-41 and SBA15 have been intensified. MCM- 41 is a silicate material with one-dimensional pores of about $30 \AA$ diameter, arranged in a hexagonal form. SBA-15 is very similar to MCM41, but have larger pores of around 60-70 $\AA$ and thicker walls, becoming structurally more stable. The catalyst immobilization on mesoporous supports is usually done using the direct impregnation or the methylaluminoxane (MAO) pre-treatment techniques. The efficiency of these methods is directly linked to the catalyst type and the support structure. One way to increase the stability of the heterogeneous catalyst and facilitate the formation of the active site is introducing elements such as $\mathrm{B}, \mathrm{Fe}, \mathrm{Ga}, \mathrm{Ti}, \mathrm{V}, \mathrm{Sn}$ and $\mathrm{Al}$ in the support structure, providing acidity to the material. ${ }^{14}$ Previous studies have shown that, when using the direct impregnation method, the aluminum present in MCM-41 framework may facilitate the attachment of the metallocene catalyst $\left(\mathrm{Cp}_{2} \mathrm{ZrCl}_{2}\right)$ to the support and promote active species formation more easily compared with the pure siliceous support. However, a very high Al content in the framework of the support can be detrimental to the catalytic activity and an optimal acidity level must be achieved for maximum polymerization activity. It was shown that the best ratio $\mathrm{Si} / \mathrm{Al}$ is 30. On the other hand, the modification of Al-MCM-41supports, by prior impregnation with MAO, reduces the effect of framework acidity, and in that case the presence of $\mathrm{Al}$ decreased the catalyst activity. ${ }^{15}$ More recently, Ga-MCM-41 supports were used in the ethylene polymerization together with $\mathrm{Cp}_{2} \mathrm{ZrCl}_{2}$. Similarly to $\mathrm{Al}$, the $\mathrm{Ga}$ presence in the support structure increased polymerization activity, if using direct impregnation method. ${ }^{16,17}$ These studies pointed out the determinant role that surface acidity properties of MCM-41 may play in the activation of the metallocene catalyst and on the resulting polymerization activity.

This work addresses the synthesis of a new postmetallocene titanium catalyst from ethylmaltol bidentate ligand, and the evaluation of its behavior in homogeneous and heterogeneous ethylene polymerization using distinct mesoporous silica supports and methods of immobilization. It should be noted that experimental synthesis of the new complex is simple, inexpensive and easy to obtain. The observed polymerization behavior is discussed in terms of support textural and chemical properties.

\section{Experimental}

All experiments for complex synthesis and ethylene polymerization were performed under argon or nitrogen atmosphere using the Schlenk technique. All the solvents were dried by usual methods existing in the literature. Ethylmaltol ligand (Sigma-Aldrich) and $\mathrm{TiCl}_{4}$ (Merck) were used without further purification. MAO, methylaluminoxane, (Akzo Nobel, $7 \% \mathrm{~m} / \mathrm{m} \mathrm{Al}$ in toluene solution) was employed as received.

Synthesis and characterization of the dichlorobis(3-hydroxy2-ethyl-4-pyrone)titanium(IV)complex

Tetrachloride titanium, $\mathrm{TiCl}_{4},(0.39 \mathrm{~mL}, 3.57 \mathrm{mmol})$ was added drop wise using a syringe to a solution of ethylmaltol ligand ( $1 \mathrm{~g}, 7.14 \mathrm{mmol})$ in dichloromethane under argon atmosphere. The mixture was stirred at room temperature for 2 hours. Then, the solid was washed twice with diethyl ether, dissolved in dichloromethane and recrystallized in hexane. The complex was dried under vacuum and yield $89 \%$ (an orange solid). The ${ }^{1} \mathrm{H}$ and ${ }^{13} \mathrm{C}$ NMR (nuclear magnetic resonance) spectra of the complex were recorded on a Varian Inova 300 Spectrometer, using $\mathrm{CDCl}_{3}$ as solvent. The UV-Vis absorption spectrum was recorded on a Varian Cary 100 spectrophotometer with quartz cells of $1 \mathrm{~cm}$ path length at room temperature. The analysis was performed using toluene as solvent with $5 \times 10^{-4} \mathrm{~mol} \mathrm{~L}^{-1}$ sample concentration. Elemental analysis 
$(\mathrm{C}, \mathrm{H})$ was performed in a 240 PerkinElmer. Anal. calcd. for $\mathrm{C}_{14} \mathrm{H}_{14} \mathrm{O}_{6} \mathrm{TiCl}_{2}\left(\mathrm{M}=396.94 \mathrm{~g} \mathrm{~mol}^{-1}\right)$ : C 42.32, H 3.53; found: C 43.00, H 3.75; ${ }^{1} \mathrm{H} \mathrm{NMR}\left(300 \mathrm{MHz}, \mathrm{CDCl}_{3}\right) \delta 8.06$ (d, $1 \mathrm{H}, J 5.1 \mathrm{~Hz}, \mathrm{H}_{6}$, isomer A), $7.32\left(\mathrm{~d}, 1 \mathrm{H}, J 6.2 \mathrm{~Hz}, \mathrm{H}_{6}\right.$, isomer B), $7.19\left(\mathrm{~d}, 1 \mathrm{H}, J 6.1 \mathrm{~Hz}, \mathrm{H}_{6}\right.$, isomer C), $6.65(\mathrm{~d}, 1 \mathrm{H}$, $J 5.1 \mathrm{~Hz}, \mathrm{H}_{5}$, isomer A), $6.07\left(\mathrm{~d}, 1 \mathrm{H}, J 6.2 \mathrm{~Hz}, \mathrm{H}_{5}\right.$, isomer B), $5.76\left(\mathrm{~d}, 1 \mathrm{H}, J 6.1 \mathrm{~Hz}, \mathrm{H}_{5}\right.$, isomer C), 3.49 (q, J 7.0 Hz, $\mathrm{H}_{7}$, isomer A), $2.91\left(\mathrm{q}, J 7.6 \mathrm{~Hz}, 2 \mathrm{H}, \mathrm{H}_{7}\right.$, isomer $\left.\mathrm{B}\right), 2.46$ (q, $2 \mathrm{H}, J 7.3 \mathrm{~Hz}, 2 \mathrm{H}, \mathrm{H}_{7}$, isomer C), 1.21 (t, $3 \mathrm{H}, J 7.0 \mathrm{~Hz}, \mathrm{H}_{8}$, isomer A), $1.31\left(\mathrm{t}, 3 \mathrm{H}, J 7.6 \mathrm{~Hz}, \mathrm{H}_{8}\right.$, isomer $\left.\mathrm{B}\right) ;{ }^{13} \mathrm{C} \mathrm{NMR}$ $\left(75 \mathrm{MHz}, \mathrm{CDCl}_{3}\right) \delta 179.16\left(\mathrm{C}_{4}, \mathrm{C}=\mathrm{O}\right), 156.65\left(\mathrm{C}_{3}\right), 156.48$ $\left(\mathrm{C}_{6}, \mathrm{CH}\right), 153.24\left(\mathrm{C}_{2}\right), 109.47\left(\mathrm{C}_{5}, \mathrm{CH}\right), 22.13\left(\mathrm{C}_{7}, \mathrm{CH}_{2}\right)$, $10.66\left(\mathrm{C}_{8}, \mathrm{CH}_{3}\right)$.

\section{Theoretical calculations for complex}

The geometries and energies of all possible isomeric species of the complex, and their conformers, were obtained by full unconstrained optimizations performed at density functional theory (DFT) level using the B3LYP hybrid functional obtained by the three parameter fit of the exchange-correlation potential suggested by Becke ${ }^{18}$ and the gradient corrected correlation functional of Lee, Yang and Parr. ${ }^{19}$ The polarized Dunning-Huzinaga DZ basis $\operatorname{set}^{20,21}$ was used for the hydrogen, carbon, oxygen and chlorine atoms. For the titanium atom the inner shell electrons were represented by the Los Alamos effective core potential (LANL2) of Hay and $\mathrm{Wadt}^{22,23}$ and the valence electrons were explicitly included using the associated DZ basis set. All calculations were performed with the Gaussian 03 program using standard procedures and parameters. ${ }^{24}$

\section{Preparation and characterization of the mesoporous solids}

The synthesis of pure SBA-15 support is described below. A portion of $13.2 \mathrm{~g}$ of P-123 [(poly(ethyleneglycol)block-poly(propyleneglycol)-block-poly(ethyleneglycol)], (Aldrich) were dissolved in $500 \mathrm{~mL}$ of water and kept stirring during the night, at room temperature. The temperature was raised to $40{ }^{\circ} \mathrm{C}$ and then $45 \mathrm{~mL}$ of chloridric acid (37\% aq. sol.) and $30.8 \mathrm{~g}$ of tetraethyl orthosilicate (TEOS, Aldrich) were added. After ca. 2 h, $12.3 \mathrm{~g}$ of $\mathrm{NaCl}$ were added and the final mixture was kept under stirring at $40{ }^{\circ} \mathrm{C}$ for more 22 hours. Subsequently, the compound was crystallized at $100{ }^{\circ} \mathrm{C}$ during three days in a polypropylene bottle. Later, the mixture was washed until pH 6-7. Aluminium-containing SBA-15 was prepared according to the literature. ${ }^{25}$ In a typical experiment, for instance, for a $\mathrm{Si} / \mathrm{Al}=10$ ratio in the synthesis gel, $10 \mathrm{~g}$ of P-123 (Aldrich) was dissolved in $432 \mathrm{~g}$ of water and then it was added $11.52 \mathrm{~g}$ of aluminium sulfate $\left(18 \mathrm{H}_{2} \mathrm{O}\right)$
(M: $666.43 \mathrm{~g} \mathrm{~mol}^{-1}$, Aldrich). The mixture was left under magnetic stirring for 1 hour at room temperature. After this time, $36 \mathrm{~g}$ of TEOS (Aldrich) were added and stirred for $16 \mathrm{~h}$ at room temperature. Finally the mixture was kept for $48 \mathrm{~h}$ at $100{ }^{\circ} \mathrm{C}$.

The detailed synthesis procedure of the different MCM-41 supports is described in the literature for micro siliceous MCM-41, aluminium-containing MCM-41 (direct synthesis $)^{26}$ and MCM-41 nanoparticles. ${ }^{27}$

All templates were partially removed by extraction with $96 \%$ ethanol at reflux temperature for $16 \mathrm{~h}$. All solid mesoporous supports were calcinated under a flux $\left(6 \mathrm{~L} \mathrm{~g} \mathrm{~g}^{-1} \mathrm{~h}^{-1}\right)$ of dry air at $550{ }^{\circ} \mathrm{C}$ for $12 \mathrm{~h}$. The temperature was increased from 20 to $550{ }^{\circ} \mathrm{C}$ at $5{ }^{\circ} \mathrm{C} \mathrm{min}^{-1}$.

The aluminated SBA-15 and MCM-41 supports with $\mathrm{Si} / \mathrm{Al}$ ratios of 33 and 35 determined by bulk elemental analysis, will be referred as Al-SBA-15/33 and Al-MCM-41/35, respectively. Purely silicious micrometric and nanometric MCM-41 will be referred to as MCM41 nano and MCM-41micro, respectively.

Powder XRD patterns were recorded on Panalytical $\mathrm{X}^{\prime}$ Pert Pro diffractometer using $\mathrm{CuK} \alpha$ radiation filtered by $\mathrm{Ni}$ and an $\mathrm{X}^{\prime}$ Celerator detector. Nitrogen adsorption isotherms were measured at $-196{ }^{\circ} \mathrm{C}$ using ASAP 2010 Micromeritics equipment. Scanning electron microscopy (SEM) images were obtained on a JEOL JSM-7001F equipment. Transmission electron microscopy (TEM) images were obtained in Hitachi H8100 equipment. Samples were deposited in a $\mathrm{Cu} /$ polymer grid sample holder.

\section{Preparation of the supported catalysts}

Prior to use, the supports were dried in a reactor by heating at $5{ }^{\circ} \mathrm{C} \mathrm{min}{ }^{-1}$ till $400{ }^{\circ} \mathrm{C}$ with reconstituted air ( $4 \mathrm{~L} \mathrm{~g}^{-1} \mathrm{~h}^{-1}$ ) during 1 hour. Then, the supports were kept at the same temperature during another $1 \mathrm{~h}$ under a nitrogen flow ( $4 \mathrm{~L} \mathrm{~g}^{-1} \mathrm{~h}^{-1}$ ) and finally cooled to room temperature. The solids were transferred and stored under nitrogen in a Schlenk flask and used as catalyst supports according to methods A and B, detailed below.

\section{Method A (direct impregnation of the Ti complex)}

A solution of $2.8 \mu \mathrm{mol}$ of catalyst in toluene (in previous tests it was showed that this concentration is lower than the maximal load of Ti that the support can afford) was added to a suspension of $200 \mathrm{mg}$ of the mesoporous solid in toluene and stirred for $10 \mathrm{~min}$. After this contact time the catalyst suspension is allowed to deposit the solids. If the initial yellow catalyst solution turned out colorless and the deposited silica support becomes yellowish this indicates that the catalyst was 
fixed on the support. Otherwise more time of reaction or a smaller load of the titanium complex should be chosen. Additional experiments were made to confirm that the titanium was fully immobilized and that no leaching was occurring. These comprised: (i) polymerization tests with the clear supernatant liquid, i.e., the clarified solution, showing no polymerization activity whereas the remaining catalyst slurry (containing the solid catalyst part) showed normal polymerization activity; and (ii) elemental analysis of the solid support and of the clarified solvent were performed showing that no Ti is detected in the clarified solvent and that the Ti content on the solid support agrees well with the expected value.

\section{Method B (impregnation of MAO pre-activated Ti complex)}

The solution of catalyst in toluene is pre-activated with MAO $(\mathrm{Al} / \mathrm{Ti}=150)$ by stirring for $15 \mathrm{~min}$ at room temperature. After this time, the equivalent of $2.8 \mu \mathrm{mol}$ of MAO pre-treated catalyst is mixed with $200 \mathrm{mg}$ of the support in toluene and stirred for $10 \mathrm{~min}$. As in method A, the fully immobilization of Ti was confirmed.

\section{Ethylene polymerizations and polymer characterization}

The reactions were performed in a glass bottle reactor (Wilmad LabGlass LG-921) with $250 \mathrm{~mL}$ capacity, magnetic stirrer and controlled temperature. The reactor was filled with $50 \mathrm{~mL}$ of toluene, the co-catalyst MAO (co-catalyst/ catalyst ratio: 500), the catalyst and ethylene (atmospheric pressure). There were used $3 \mu \mathrm{mol}$ of homogeneous catalyst or $2.8 \mu \mathrm{mol}$ of supported (heterogeneous) catalyst. During the reaction, the temperature, pressure and ethylene mass flow data were real-time monitored and the data stored. The ethylene mass flow units were SLPM (standard liter per minute) and they were converted to ethylene consumption with the units $\mathrm{kg} P \mathrm{PE} \mathrm{mol}^{-1} \mathrm{~h}^{-1}$. The kinetic profiles correspond to ethylene consumption data versus time.
The integral of the obtained curve in function of time corresponds to the average value of the activity, and agrees well with the weight of the recovered polymer. At the end, the reactor is discharged and the polymer is precipitated over methanol acidified with $\mathrm{HCl}$, and further washed twice with fresh methanol, before drying.

The melting points $\left(\mathrm{T}_{\mathrm{m}}\right)$ and crystallinities $\left(\mathrm{X}_{\mathrm{c}}\right)$ of the polymers were determined using a differential scanning calorimeter DSC Q20 TA Instruments from 20 to $160^{\circ} \mathrm{C}$ and a heating rate of $10{ }^{\circ} \mathrm{C} \mathrm{min}^{-1}$ with $50 \mathrm{~mL} \mathrm{~min}^{-1}$ of $\mathrm{N}_{2}$ flow rate. The heating cycle was performed twice, but only the results of the last scan were considered.

The molecular weights were estimated using a Waters Alliance GPC 2000 instrument equipped with three Styragel HT-type columns (HT3, HT5, and HT6E). 1,2,4-Trichlorobenzene was used as solvent, at a flow rate of $1 \mathrm{~mL} \mathrm{~min}{ }^{-1}$ and temperature of $135{ }^{\circ} \mathrm{C}$. The columns were calibrated with polystyrene standards.

\section{Results and Discussion}

The dichlorobis(3-hydroxy-2-ethyl-4-pyrone) titanium(IV) complex was synthesized from ethylmaltol ligand and $\mathrm{TiCl}_{4}$ in dichloromethane, as shown in Scheme 1.

The elementary analysis, ${ }^{1} \mathrm{H}$ and ${ }^{13} \mathrm{C}$ NMR spectra (see Experimental section) are in accordance with this complex structure.

Figure 1 shows ${ }^{1} \mathrm{H}$ NMR spectra of the ethylmaltol ligand and complex. Ligand spectrum shows the presence of the proton signal of the hydroxyl group at $6.65 \mathrm{ppm}$. This signal is absent in the complex spectrum due to deprotonation caused by titanium insertion as it is shown in Scheme 1. The metal insertion to form the complex causes a shift of $\mathrm{H} 5$ and $\mathrm{H} 6$ resonances to higher frequencies in relation to the ligand spectrum, indicating the deshielding of the aromatic protons due to the donation of electronic density to the metal.

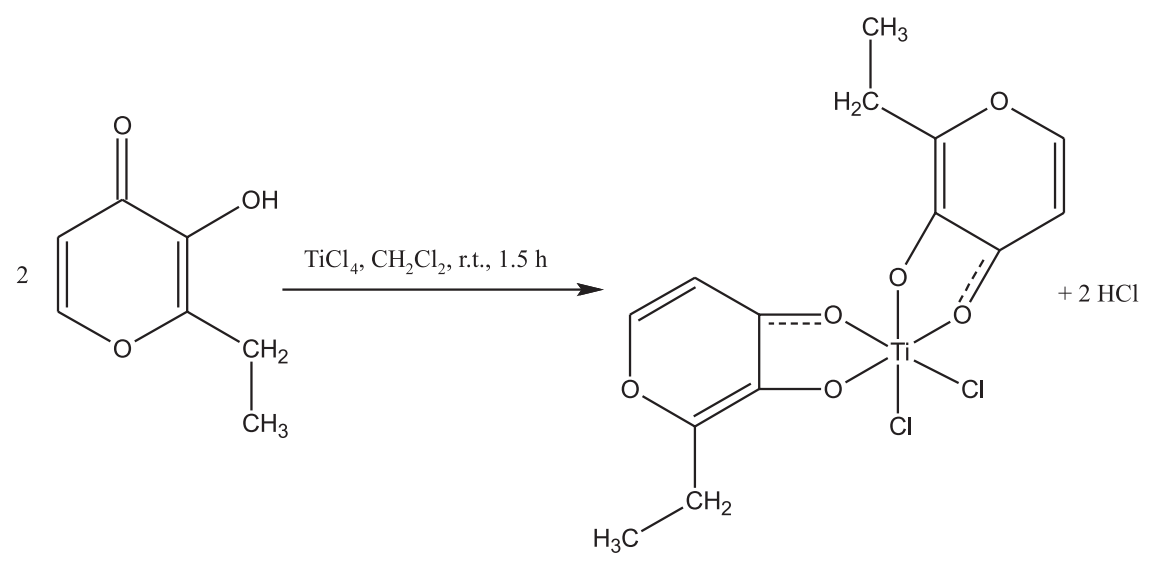




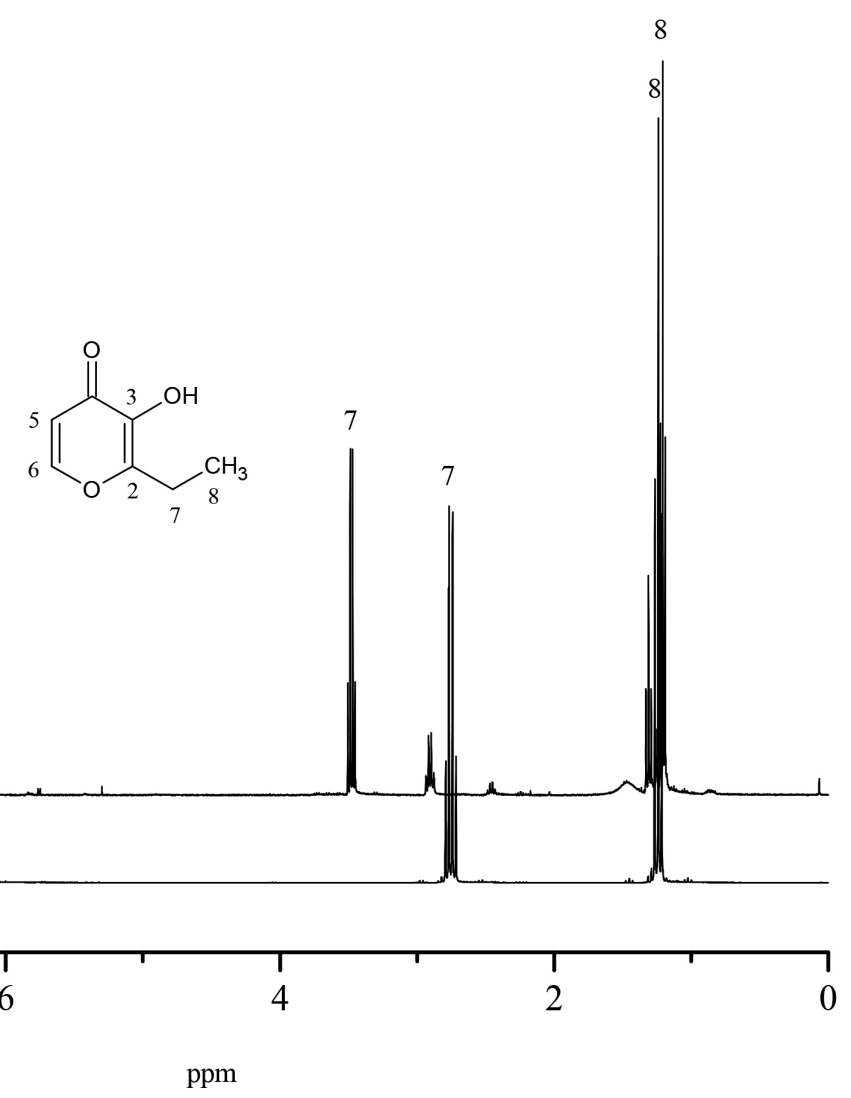

Figure 1. ${ }^{1} \mathrm{H}$ NMR spectra of the ethylmaltol ligand and complex in $\mathrm{CDCl}_{3}$.

The expanded ${ }^{1} \mathrm{H}$ RMN spectra, Figure 2, suggest the existence of three isomers for the complex, A $(74.7 \%)$, B (16.8\%) and $\mathrm{C}(8.5 \%)$.

The existence of isomers is also foreseen by the theoretical calculations using density functional theory (DFT). The relative energies related to the lowest energy configuration and the estimated population percentage of each species of isomer considering a temperature of $25^{\circ} \mathrm{C}$ are shown in Table 1. The calculations indicate the existence of five different stable geometric isomers arising from different arrangements of chlorine atoms with respect to the titanium complex. Two isomers show trans configuration and three isomers show cis configuration. The most stable isomer is the Cis 2; among all other calculated isomeric structures, only Cis 1 and Cis 2 configuration showed relative energy lower than $2 \mathrm{kcal} \mathrm{mol}^{-1}$ and population percentage up to $0.01 \%$.

Figure 3 shows all the calculated possible isomeric structures for complex. These calculations estimate that isomer Cis 2 should be in greater proportion (96.33\%) followed by $\mathrm{Cis} 1$ with $3.67 \%$. Although the estimated percentages of isomers obtained by DFT are different from NMR calculations, it is good to remember that those are theoretical calculations. In fact, ${ }^{1} \mathrm{H}$ NMR spectrum shows the presence of three isomers. Probably the main isomer A is referred to Cis 2 structure while the minor isomers B and $\mathrm{C}$ can be Cis 1 and Cis 3, respectively. These complexes with chlorides in the cis position are desirable because only the cis structures are active in the olefins polymerization. ${ }^{3}$ Therefore, all the isomers obtained in the complex synthesis can be considered active in ethylene polymerization reactions.

The complex was also characterized by UV-Vis spectroscopy. The ligand shows a narrow and intense peak with maximum absorption at $\lambda_{\max }=286 \mathrm{~nm}\left(\pi \rightarrow \pi^{*}\right)$ and a less intense broadband at $\lambda_{\max }=335 \mathrm{~nm}\left(\mathrm{n} \rightarrow \pi^{*}\right)$. The complex spectrum shows two relatively wider bandwidths than the ligand, displaced to higher wavelengths. The first band of the complex shows maximum absorption at $\lambda_{\max }=293 \mathrm{~nm}$ while the second band is observed at $\lambda_{\max }=357 \mathrm{~nm}$. The appearance of these wider bands suggests, a ligand charge transfer to the metal showing the ligand coordination to the metal. ${ }^{28}$ There were not found in the literature studies using UV-Vis spectroscopy of analogous complexes to compare with the results presented here. Furthermore analogous complexes available in the literature were diluted in another solvent than toluene.

Five mesoporous supports exhibiting different textural and/or chemical features were studied in this work. 

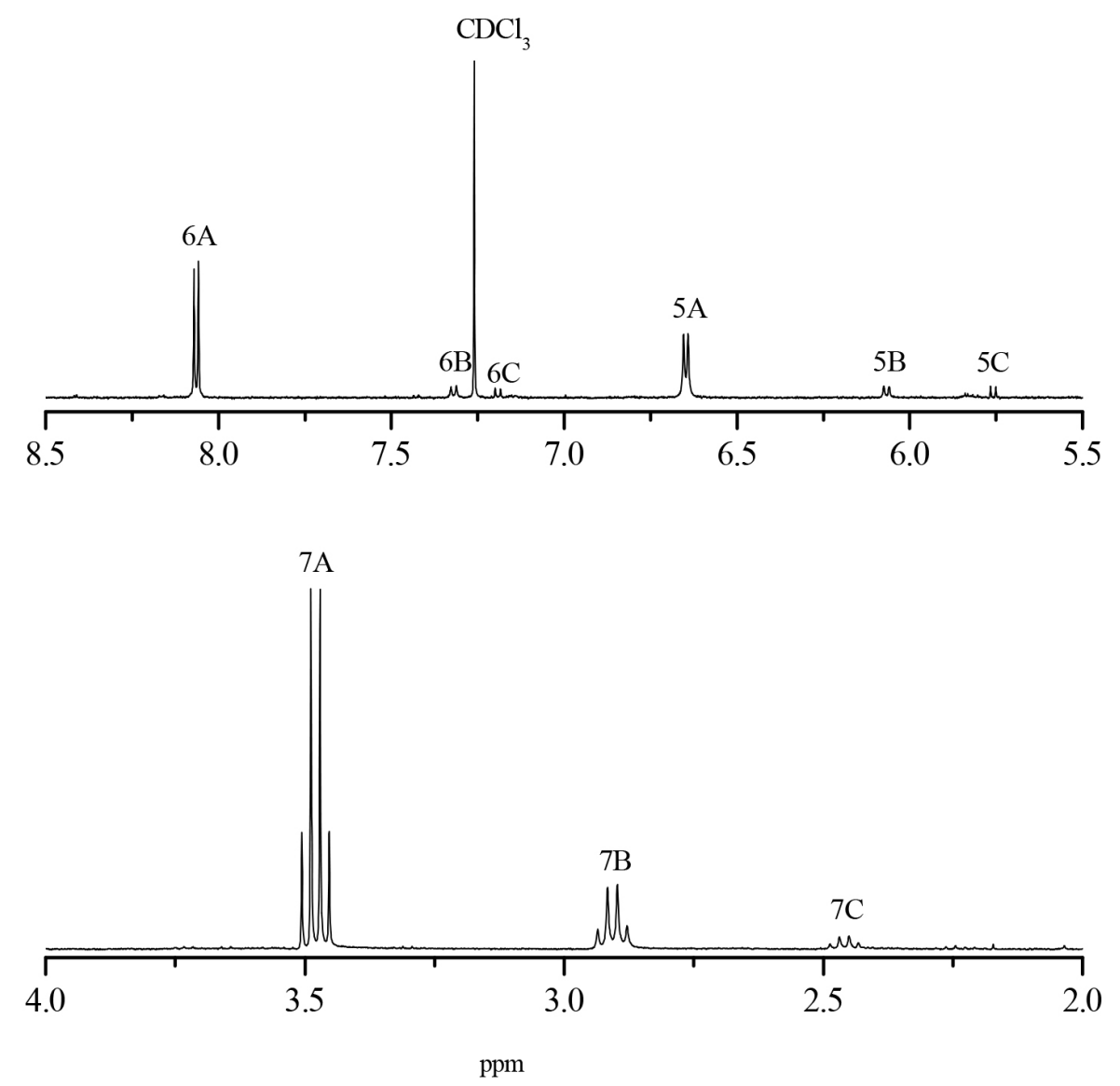

Figure 2. ${ }^{1} \mathrm{H}$ NMR expanded spectra of the complex in $\mathrm{CDCl}_{3}$.

Table 1. Molecular energies and energies relating to more stable configurations of complex

\begin{tabular}{lccc}
\hline Isomer & Energy / hartree & $\begin{array}{c}\text { Relative energy / } \\
\left(\mathrm{kcal} \mathrm{mol}^{-1}\right)\end{array}$ & Population $^{\mathrm{a}}$ \% \\
\hline Trans 1 & $-1693,8065209$ & 9,794 & 0.00 \\
Trans 2 & $-1693,8113058$ & 6,791 & 0.00 \\
Cis 1 & $-1693,8190431$ & 1,936 & 3.67 \\
Cis 2 & $-1693,8221281$ & 0,000 & 96.33 \\
Cis 3 & $-1693,8124134$ & 6,096 & 0.00 \\
\hline
\end{tabular}

${ }^{\text {aAt }}$ room temperature, $298 \mathrm{~K}$.

Figure 4 shows TEM and SEM micrographs of MCM-41 based supports. MCM-41nano exhibits regular spherical particles with diameters below $100 \mathrm{~nm}$, while MCM-41micro presents particle aggregates formed from primary particles with an average size of $1 \mu \mathrm{m}$ and irregular morphology. The incorporation of Al into MCM-41 structure leads to a decrease of the primary particle size and to an increase of the particle irregularity. A less regular morphology is also observed when Al-SBA-15/33 is compared with pure siliceous SBA-15, Figure 5. TEM micrographs clearly show the presence of a porous structure for all the supports, with a high ordering in the case of MCM-41micro and SBA- 15 .

X-Ray diffraction (XRD) patterns of the different supports are shown in Figure 6. SBA-15, Al-SBA-33 and MCM-41micro materials exhibit diffraction peaks characteristic of a highly ordered hexagonal mesoporous structure. The narrower and higher intensity peak corresponds to the plane (100) while the other less intense peaks correspond to the planes (110) and (200), respectively. ${ }^{29-31}$ Incorporation of aluminum in SBA-15 does not appear to significantly change the original crystalline support structure. On the other hand, the incorporation of Al in MCM- 41 causes a broadening of the diffraction peaks, which is indicative of some distortion in the hexagonal structure. ${ }^{15} \mathrm{MCM}-41$ nano, Figure 6b, shows a less intense and broader (100) peak, which is expected for small-size particles and/or a disordered porous structure due to the spherical particle shape. ${ }^{27}$

Nitrogen adsorption data, Table 2, shows, for all the samples, a high Brunauer-Emmett-Teller (BET) surface area and, as expected, significant differences in other textural parameters. A higher pore diameter and higher pore volume is observed for SBA-15 and Al-SBA-15/33, when compared with the other materials. On the other 


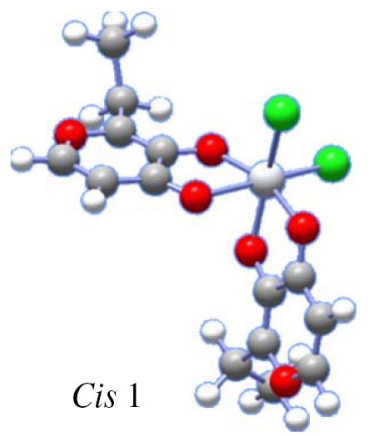

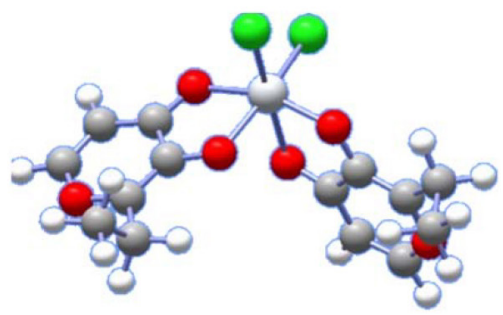

Cis 2

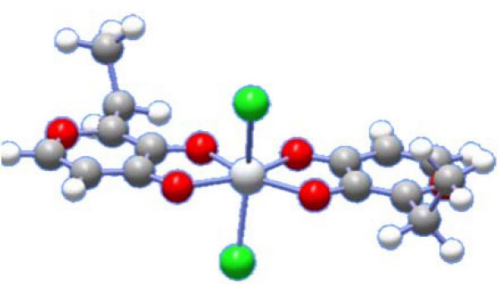

Trans 1
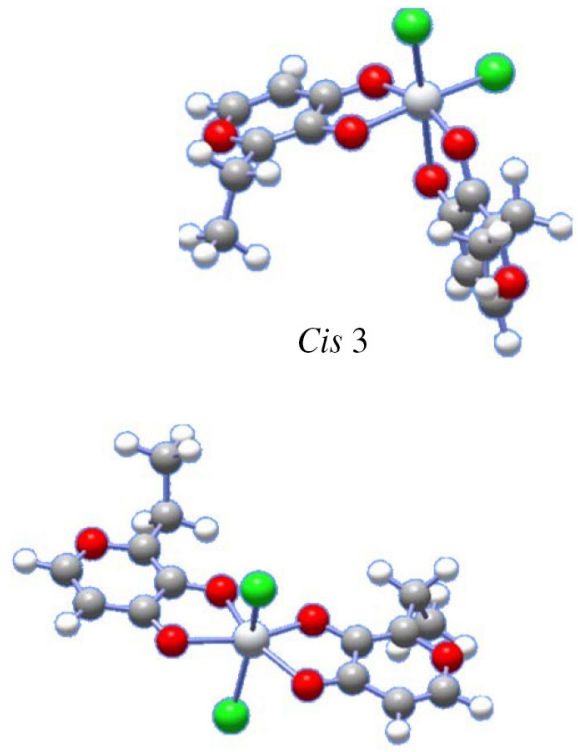

Trans 2

Figure 3. Structures of the possible isomers of complex.
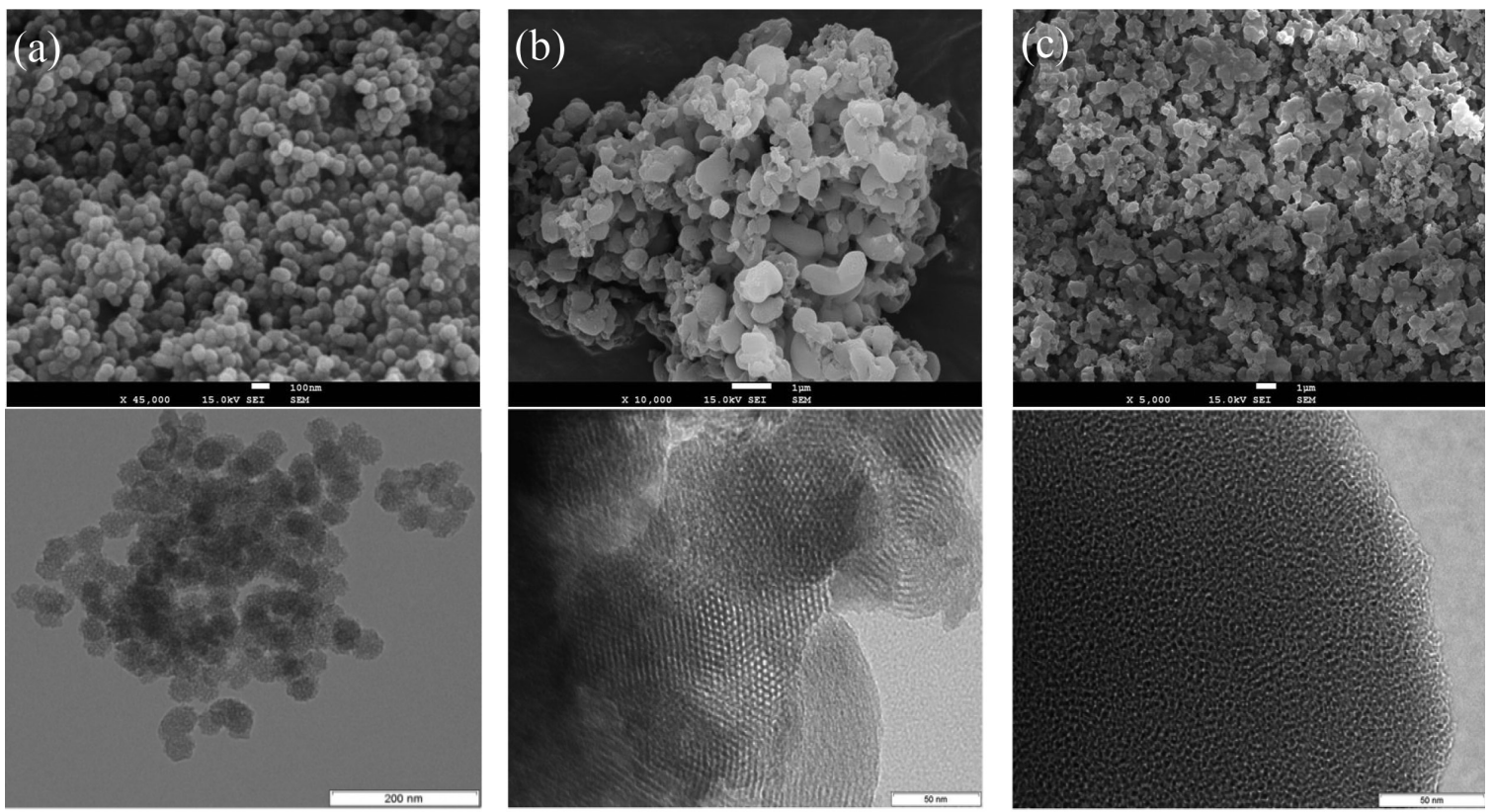

Figure 4. SEM (up) and TEM (down) micrographs of the MCM mesoporous solids: (a) MCM-41 nano; (b) MCM-41 micro; (c) Al-MCM-41/35.
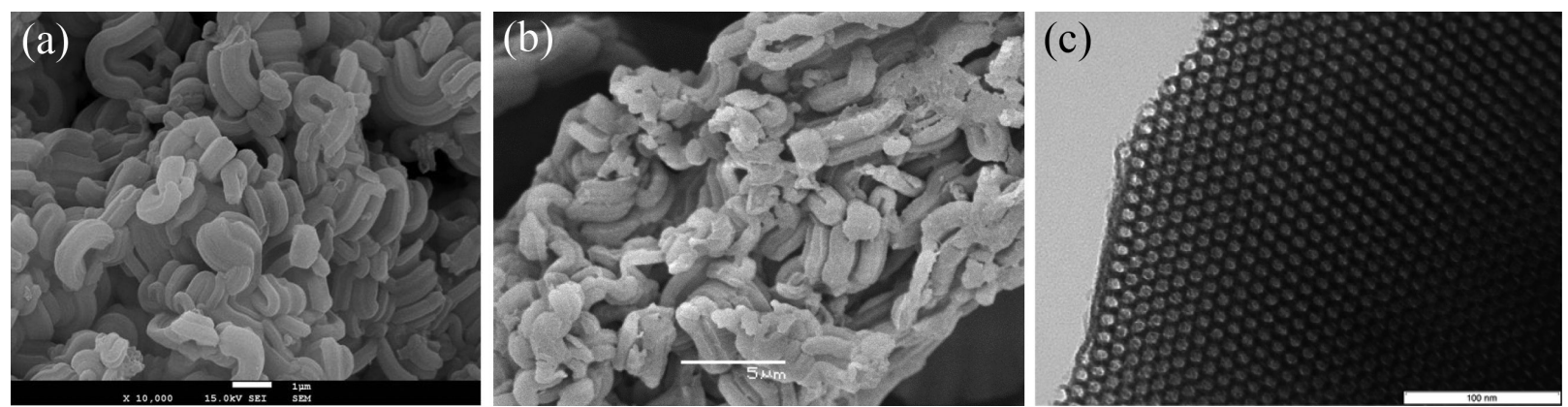

Figure 5. Micrographs of SBA: (a) SEM of SBA-15; (b) SEM of Al-SBA-15/33; (c) TEM of SBA-15. 

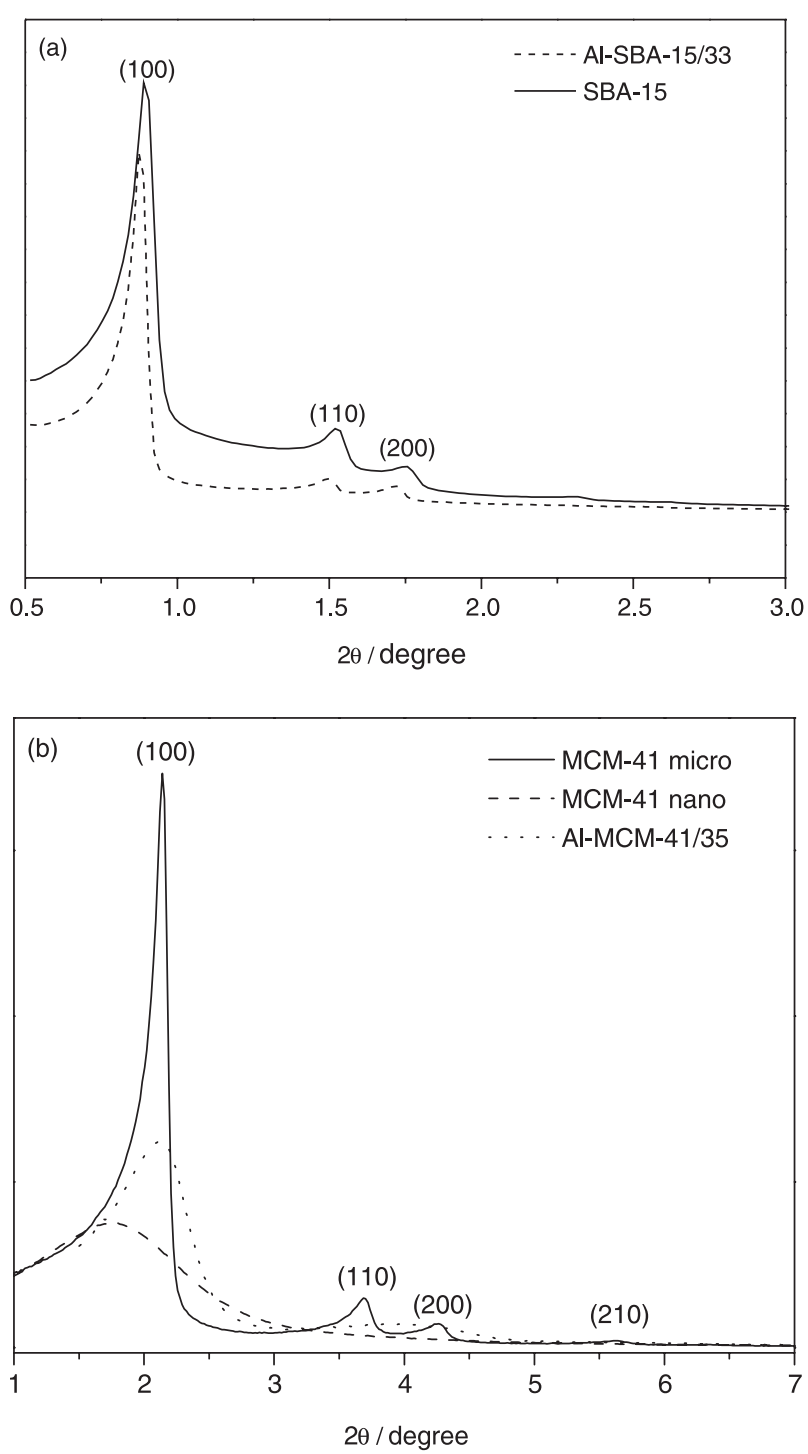

Figure 6. XRD patterns of supports: (a) pure SBA-15 and aluminumcontaining SBA-15; (b) MCM-41nano, MCM-41micro and aluminumcontaining MCM-41.

hand, MCM-41nano shows the lowest pore volume and the highest external surface area, due to the morphology and size of the particles. For each material type the introduction of $\mathrm{Al}$ atoms in the silica framework does not lead to significant changes on the textural parameters.
The new complex synthesized was tested in the ethylene polymerization in both homogeneous and heterogeneous systems. In this study we used two methods for immobilization: direct impregnation of Ti complex, method $\mathrm{A}$, and impregnation of MAO pre-activated $\mathrm{Ti}$ complex, method B.

In Figure 7 the kinetic profiles obtained for the heterogeneous systems prepared by method $\mathrm{B}(\mathrm{Al} / \mathrm{Ti}=500)$ are shown. The average activity for each polymerization reaction was obtained by integration of the corresponding kinetic profile over the time reaction. All mesoporous supports showed similar kinetic profiles with higher activity at the beginning of the polymerization and lower activity over time.

The values for the average polymerization activity at $\mathrm{Al} / \mathrm{Ti}=500$ obtained for the homogeneous $\mathrm{Ti}$ complex and for the derived heterogeneous catalytic systems are compared in Figure 8.

Polymerization reaction results show that the heterogeneous systems are more active than the homogeneous one independent of the support and method used. However polymerization activities obtained with method A remain at relatively low levels and differences between the various supports used are not significant. When using method B much higher activities are obtained suggesting that the role of the silica support is more effective if MAO/Ti complex pre-activation occurs prior to the immobilization process. This may indicate that the mesoporous silica network is able either to potentiate the reactivity of pre-formed active sites and/or to stabilize and prevent them from subsequent deactivation processes. On the other hand, due to the higher polymerization activities observed for this method, the effect of the type of support used on the activity is much more evident. The observed results can be understood taking into account the changes on textural and chemical properties of the supports. ${ }^{14}$

In fact, for pure siliceous supports, the lower polymerization activity observed for MCM-41micro, compared to MCM-41nano or SBA-15, can result partially from some diffusion resistance operating in microsized

Table 2. Parameters of the mesoporous materials used as support

\begin{tabular}{|c|c|c|c|c|}
\hline Support & $\mathrm{S}_{\mathrm{BET}} /\left(\mathrm{m}^{2} \mathrm{~g}^{-1}\right)$ & $\mathrm{V}_{\mathrm{p}} /\left(\mathrm{cm}^{3} \mathrm{~g}^{-1}\right)$ & $\mathrm{A}_{\text {ext }} /\left(\mathrm{m}^{2} \mathrm{~g}^{-1}\right)$ & $\mathrm{D}_{\mathrm{p}} / \AA$ \\
\hline MCM-41nano ${ }^{19}$ & 726 & 0.35 & 175 & 26 \\
\hline MCM-41micro ${ }^{19}$ & 873 & 0.68 & 44 & 28 \\
\hline Al-MCM-41/35 & 927 & 0.70 & 58 & 27 \\
\hline SBA-15 & 743 & 1.12 & 87 & 70 \\
\hline Al-SBA-15/33 & 774 & 0.91 & 53 & 65 \\
\hline
\end{tabular}

$\mathrm{S}_{\mathrm{BET}}$ : specific surface area; $\mathrm{V}_{\mathrm{p}}$ : specific pore volume (calculated using the t-plot method); external area (calculated using the t-plot method); $\mathrm{D}_{\mathrm{p}}$ : average pore diameter (calculated using the Barrett-Joyner-Halenda (BJH) method). 


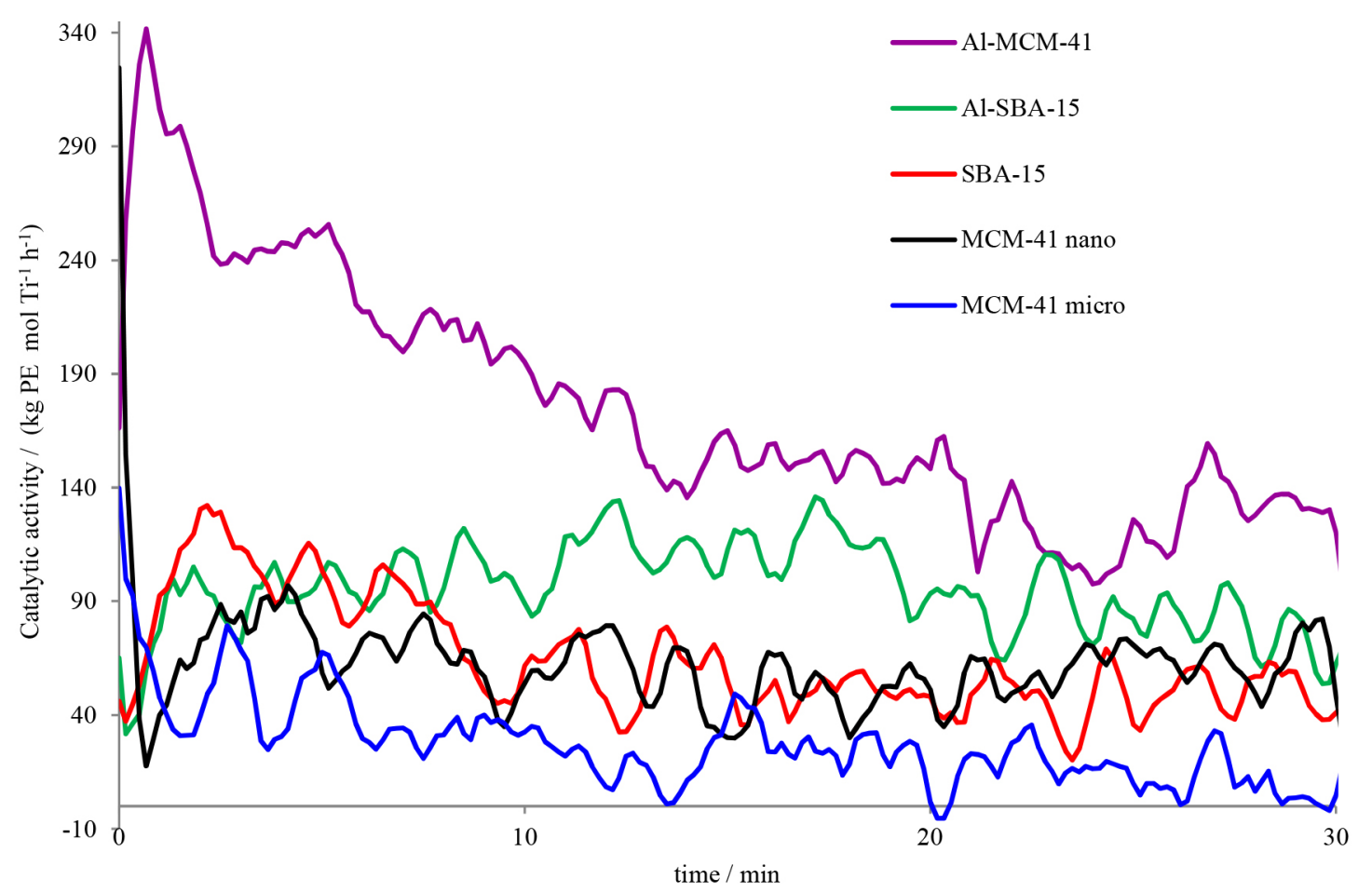

Figure 7. Set of kinetic profiles obtained for the ethylene polymerization runs performed with the catalytic systems prepared with method $\mathrm{B}, \mathrm{Al} / \mathrm{Ti}=500$.

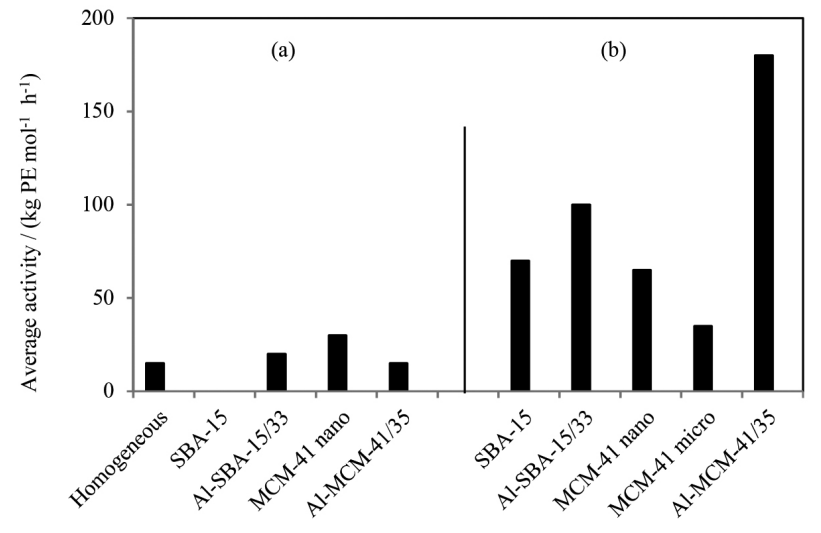

Figure 8. Average activity of the ethylene polymerization catalyzed by new complex: (a) method A; (b) method B (solvent: toluene, $50 \mathrm{~mL}$; time: $0.5 \mathrm{~h}$; temperature: $40^{\circ} \mathrm{C}$; ethylene pressure: $\left.1.1 \mathrm{~atm}\right)$.

MCM-41 support. As shown in Table 2 MCM-41micro and nano do not differ significantly in their specific surface area or pore diameter but the external surface area is much higher for the nano sized particles, making more accessible a major part of its active sites. Another factor to be taken in account is that MCM-41 micro and nanoparticles (prepared by different synthetic methods) exhibit differences in terms of the surface density of $\mathrm{OH}$ groups, being the ratio between isolated/vicinal $\mathrm{OH}$ groups higher for the nanometric support. ${ }^{27}$ This may favor the ratio between active and inactive centers formed upon immobilization and accordingly increase the activity. When comparing MCM-41 to SBA-15 no changes on the distribution of surface $-\mathrm{OH}$ groups were detected. Therefore the higher external area and pore diameter exhibited by SBA- 15 will facilitate active site accessibility and most probably will account for the higher activity observed.

The addition of aluminum to the MCM-41 and SBA-15 framework leads to a further increase of the activity of the supported systems. The observed behavior is in agreement with previous studies using Al-MCM-41 and Ga-MCM-41 supports for zirconocene immobilization via direct impregnation route. ${ }^{14,15}$ It was shown that the presence of aluminum or gallium on MCM-41 changes the framework acidity and favors the fixation of the titanium complex on the support facilitating this way the formation of active species on Lewis acid sites and improving polymerization activity. An optimal value of Si/Al ratio of 30 was found, leading to the highest polymerization activities. ${ }^{15}$ It was also demonstrated that the $\mathrm{Si} / \mathrm{Al}$ ratio played an additional positive effect on polymerization activity through its influence on the active centers stability. For SBA-15 the effect of aluminum introduction is not so strong. This feature could be related to a lower acidity of the Al-SBA-15 when compared to Al-MCM-41.

The polymers obtained by the new catalytic system showed melting points around $131-134{ }^{\circ} \mathrm{C}$, typical of high density polyethylene. The molecular weight of polyethylene obtained by the homogeneous system was high $\left(331.000 \mathrm{~g} \mathrm{~mol}^{-1}\right)$ with a polydispersity of 4.3 , which suggests the presence of more than one active site. Due to 
the difficulties to measure molecular weights of polymers obtained with supported systems without damage of the gel permeation chromatography (GPC) columns, there was only obtained the molecular weight of the polyethylene with the catalyst supported on SBA-15 (previous extraction with decalin in Soxhlet). The result of the molecular weight and the polydispersity was $361.000 \mathrm{~g} \mathrm{~mol}^{-1}$ and 5 , respectively. This result does not differ significantly from the molecular weight and polydispersity obtained previously with the homogeneous system.

The catalytic activity of the homogeneous reaction of the new ethylpyrone Ti complex was compared to the one obtained with the methylpyrone $\mathrm{Ti}$ analogue $\left(66 \mathrm{~kg} \mathrm{PE} \mathrm{mol}{ }^{-1} \mathrm{~atm}^{-1} \mathrm{~h}^{-1}\right)$ from a previous work. ${ }^{3} \mathrm{~A}$ polymerization reaction was performed at the same reactional conditions ( $\mathrm{Al} / \mathrm{Zr}$ : 1000; ethylene: $1.6 \mathrm{~atm}$; temperature: $40{ }^{\circ} \mathrm{C}$; time: $60 \mathrm{~min}$ ) and the result of was $237 \mathrm{~kg} \mathrm{PE} \mathrm{mol}^{-1} \mathrm{~atm}^{-1} \mathrm{~h}^{-1}$ confirming that the ethyl substituent has a positive effect on the catalytic activity of these type of catalysts.

\section{Conclusions}

A new one-step synthesis of a complex active in homogeneous or heterogeneous ethylene polymerization was performed. Catalytic activities increased considerably when the catalyst was immobilized in mesoporous silica supports. These results suggest that the mesoporous silica network is able either to potentiate the reactivity of the pre-formed active sites and/or to stabilize them. Method B, involving the impregnation of the MAO pre-activated Ti complex on the silica support, affords the best polymerization activities. The differences between the activities of the various heterogeneous catalytic systems can be understood taking into account changes on chemical composition, surface acidity, surface density of $\mathrm{OH}$ groups and textural properties of the supports. The highest polymerization activities were obtained for MCM-41 and SBA-15 supports modified by aluminum. The ethylene polymerization resulted in high density polyethylene with molecular weight around $350.000 \mathrm{~g} \mathrm{~mol}^{-1}$ and polydispersities of 4-5.

This simple and low cost synthesis of a new catalytic system for polyethylene can be an alternative to the laborious catalyst synthesis existing nowadays in the industry.

\section{Acknowledgments}

We thank CAPES, FAPERGS-PRONEX and CNPq for financial support. The authors thank Prof Raúl Quijada from Universidad de Chile for GPC measurements.

\section{References}

1. Carone, C. L. P.; Lima, V.; Albuquerque, F.; Nunes, P.; Lemos, C.; Santos, J. H. Z.; Galland, G. B.; Stedile, F. C.; Einloft, S.; Basso, N. R. S.; J. Mol. Catal. A: Chem. 2004, 208, 285.

2. Greco, P. P.; Brambilla, R.; Einloft, S.; Stedile, F. C.; Galland, G. B.; Santos, J. H. Z.; Basso, N. R. S.; J. Mol. Catal. A: Chem. 2005, 240, 61.

3. Basso, N. R. S.; Greco, P. P.; Carone, C. L. P.; Livotto, P. R.; Simplício, L. M. T.; Rocha, Z. N.; Galland, G. B.; Santos, J. H. Z.; J. Mol. Catal. A: Chem. 2007, 267, 129.

4. Fim, F. C.; Machado, T.; Sá, D. S.; Livotto, P. R.; Rocha, Z. N.; Basso, N. R. S.; Galland, G. B.; J. Polym. Sci., Part A: Polym. Chem. 2008, 46, 3830.

5. Gheno, G.; Basso, N. R. S.; Ceschi, M. A.; Livotto, P. R.; Nascimento, A. A.; Rocha, Z. N.; Galland, G. B.; Appl. Catal., A 2013, 467, 439.

6. Arnarp, J.; Bielawski, J.; Dahlin, B. M.; Dahlman, O.; Enzell, C. R.; Pettersson, T.; Acta Chem. Scand. 1990, 44, 916.

7. Alshehri, S.; Burgess, J.; Fawcett, J.; Parsons, S. A.; Russell, D. R.; Polyhedron 2000, 19, 399.

8. Yuen, V. G.; Caravan, P.; Gelmini, L.; Glover, N.; McNeill, J. H.; Setyawati, I. A.; Zhou, Y.; Orvig, C.; J. Inorg. Biochem. 1997, 68, 109.

9. Thompson, K. H.; Liboiron, B. D.; Sun, Y.; Bellman, K. D. D.; Setyawati, I. A.; Patrick, B. O.; Karunaratne, V.; Rawji, G.; Wheller, J.; Sutton, K.; Bhanot, S.; Cassidy, C.; McNeill, J. H.; Yuen, V. G.; Orvig, C.; J. Biol. Inorg. Chem. 2003, 8, 66.

10. Thompson, K. H.; Barta, C. A.; Orvig, C.; Chem. Soc. Rev. 2006, 35, 545.

11. Islam, M. N.; Kumbhar, A. A.; Kumbhar, A. S.; Zeller, M.; Butcher, R. J.; Dusane, M. B.; Joshi, B. N.; Inorg. Chem. 2010, 49, 8237.

12. Reddy, V. D.; Dayal, D.; Szalda, D. J.; Cosenza, S. C.; Reddy, M. V. R.; J. Organomet. Chem. 2012, 700, 180.

13. Sobota, P.; Przybylak, K.; Utko, J.; Jerzykiewicz, L. B.; Pombeiro, A. J. L.; Silva, M. F. C. G.; Szczegot, K.; Chem.-Eur. J. 2001, 7, 951.

14. Campos, J. M.; Lourenço, J. P.; Cramail, H.; Ribeiro, M. R.; Prog. Polym. Sci. 2012, 37, 1764.

15. Campos, J. M.; Ribeiro, M. R.; Lourenço, J. P.; Fernandes, A.; J. Mol. Catal. A: Chem. 2007, 277, 93.

16. Campos, J. M.; Lourenço, J. P.; Fernandes, A.; Ribeiro, M. R.; Catal. Commun. 2008, 10, 71.

17. Campos, J. M.; Lourenço, J. P.; Fernandes, A.; Rego, A. M.; Ribeiro, M. R.; J. Mol. Catal. A: Chem. 2009, 310, 1.

18. Becke, A. D.; Phys. Rev. A 1988, 38, 3098.

19. Lee, C.; Yang, W.; Parr, R. G.; Phys. Rev. B 1988, 37, 785.

20. Dunning, T. H.; Hay, P. J.; Modern Theoretical Chemistry, $3^{\text {rd }}$ ed.; Plenum: New York, 1977. 
21. Frisch, M. J.; Pople, J. A.; Binkley, J. S.; J. Chem. Phys. 1984, $80,3265$.

22. Hay, P. J.; Wadt, W. R.; J. Chem. Phys. 1985, 82, 270.

23. Hay, P. J.; Wadt, W. R.; J. Chem. Phys. 1985, 82, 284.

24. Frisch, M. J.; Trucks, G. W.; Schlegel, H. B.; Scuseria, G. E.; Robb, M. A.; Cheeseman, J. R.; Montgomery Jr., J. A.; Vreven, T.; Kudin, K. N.; Burant, J. C.; Millam, J. M.; Iyengar, S. S.; Tomasi, J.; Barone, V.; Mennucci, B.; Cossi, M.; Scalmani, G.; Rega, N.; Petersson, G. A.; Nakatsuji, H.; Hada, M.; Ehara, M.; Toyota, K.; Fukuda, R.; Hasegawa, J.; Ishida, M.; Nakajima, T.; Honda, Y.; Kitao, O.; Nakai, H.; Klene, M.; Li, X.; Knox, J. E.; Hratchian, H. P.; Cross, J. B.; Bakken, V.; Adamo, C.; Jaramillo, J.; Gomperts, R.; Stratmann, R. E.; Yazyev, O.; Austin, A. J.; Cammi, R.; Pomelli, C.; Ochterski, J. W.; Ayala, P. Y.; Morokuma, K.; Voth, G. A.; Salvador, P.; Dannenberg, J. J.; Zakrzewski, V. G.; Dapprich, S.; Daniels, A. D.; Strain, M. C.; Farkas, O.; Malick, D. K.; Rabuck, A. D.; Raghavachari, K.; Foresman, J. B.; Ortiz, J. V.; Cui, Q.; Baboul, A. G.; Clifford, S.; Cioslowski, J.; Stefanov, B. B.; Liu, G.; Liashenko, A.; Piskorz, P.; Komaromi, I.; Martin, R. L.; Fox, D. J.; Keith, T.; AlLaham, M. A.; Peng, C. Y.; Nanayakkara, A.; Challacombe, M.; Gill, P. M. W.; Johnson, B.; Chen, W.; Wong, M. W.; Gonzalez,
C.; Pople, J. A.; Gaussian 03, Revision D.1; Gaussian, Inc., Wallingford CT, 2004.

25. Lin, S.; Shi, L.; Carrott, M. M. L. R.; Carrott, P. J. M.; Rocha, J.; Li, M. R.; Zou, X. D.; Microporous Mesoporous Mater. 2011, $142,526$.

26. Lourenço, J. P.; Fernandes, A.; Henriques, C.; Ribeiro, M. F.; Microporous Mesoporous Mater. 2006, 94, 56.

27. Bento, A.; Lourenço, J. P.; Fernandes, A.; Cerrada, M. L.; Ribeiro, M. R.; ChemCatChem. 2013, 5, 966.

28. Brito, Y. C.; Mello, V. M.; Macedo, C. C. S.; Meneghetti, M. R.; Suarez, P. A. Z.; Meneghetti, S. M. P.; Appl. Catal., A 2008, $351,24$.

29. Zhao, D.; Sun, J.; Li, Q.; Stucky, G. D.; Chem. Mater. 2000, $12,275$.

30. Kruk, M.; Jaroniec, M.; Ko, C. H.; Ryoo, R.; Chem. Mater. 2000, 12, 1961.

31. Han, Y. J.; Kim, J. M.; Stucky, G. D.; Chem. Mater. 2000, 12, 2068.

Submitted: November 26, 2015

Published online: April 1, 2016

FAPERGS/CAPES has sponsored the publication of this article. 